Volume XII, No. 2, pp. 13-21, 2011

\title{
STUDENTS' ASSESSMENT OF ONLINE LEARNING AS RELATED TO COMPUTER AND INFORMATION SYSTEMS CURRICULA
}

\author{
Paul J. Kovacs, Robert Morris University, kovacs@rmu.edu \\ Gary A. Davis, Robert Morris University, davis@rmu.edu \\ John Scarpino, Robert Morris University, scarpino@rmu.edu \\ Lisa Kovalchick, California University of Pennsylvania, kovalchick@calu.edu
}

\begin{abstract}
This paper extends a previous study (conducted by the authors at two Universities) that examined the effectiveness of online learning in Computer and Information Systems curricula. In order to further investigate the influence of various online learning formats on students, the current research includes additional data from students and probes deeper into various delivery formats. The present study addresses the following research questions: 1) Which delivery method (i.e., on-ground, online, hybrid/partially online) do students perceive as providing the best learning in regard to Computer and Information Systems subject areas? 2) For each instructional method (i.e., online, hybrid/partially online, on-ground) should schools Offer More, Keep Offerings the Same or Offer Less courses that use a particular instructional method? 3) Can a profile be developed for students who prefer the online delivery method based on the students' work habits (i.e., supervision, self-organization and interaction)?
\end{abstract}

Keywords: Online Education, Hybrid Learning, Web-Based Learning, Distance Learning, CIS Curricula

\section{INTRODUCTION}

There is little doubt that online education has emerged as a fundamental influence in educational delivery systems in recent years, particularly in higher education. Administrators in these institutions believe that online technologies help them offer education to increasing numbers of students at less expense than conventional classroom education [13]. As a result, many universities are delivering more and more online courses across a variety of disciplines.

A recent study by the Babson Survey Research Group reported that online enrollments have continued to increase at rates far in excess of the total higher education student population. The study reported that over 4.6 million students were taking at least one online course during the Fall 2008 term; a 17 percent increase over the number reported the previous year [1]. This report also noted that the 17 percent growth rate for online enrollments far exceeds the 1.2 percent growth rate of the overall higher education student population and that more than one in four students in higher education now take at least one course online. Furthermore, online education has become an important, long-term strategy for many postsecondary institutions in terms of student enrollment. In short, it is imperative that institutions of higher education provide quality online programs [1].

Many courses in Computer Information Systems (CIS) curricula involve instruction in computer programming languages, which require hands-on development and extensive drill and practice while other CIS courses entail theoretical concepts; both of these elements can require an increased interaction with CIS faculty. It is not yet clear if online learning methods are advantageous to the delivery of such course content. Furthermore, it is not clear as to what degree (if any) online learning is effective in delivering CIS-specific course content. This study is an extension of a previous study (conducted by the authors at two universities) that examined online learning in a CIS curriculum. The current study includes additional data from students by probing deeper into various delivery formats. 
Results of the previous study found that research participants rated the perceived effectiveness of partially online courses as higher than that of completely online courses. In addition, a relationship was found between taking an online class in the past and preference for the online delivery method. Although taking an online class did not directly influence a student to take another online class, students who have not taken an online class are discouraged from trying the online format. Finally, students who would be most likely to take an online course tended to have the following demographic characteristics: non-traditional or integrated student, 31 - 40 years of age, with a full-time job, enrolled as a part-time student, commuting to school and living $6-10$ miles from campus.

Specifically, the new study was conducted to answer the following research questions.

1. Which delivery method (i.e., on-ground, online, hybrid/partially online) do students perceive as providing the best learning in regard to CIS subject areas?

2. For each instructional method (i.e., online, hybrid/partially online, on-ground) should schools Offer More, Keep Offerings the Same or Offer Less courses that use a particular instructional method?

3. Can a profile be developed for students who prefer the online delivery method based on the students' work habits (i.e., supervision, self-organization and interaction)?

\section{DEFINITION OF TERMS}

For the purposes of this research, online courses are defined as those in which 100 percent of the course content is delivered online. On-ground courses (traditional or "face-to-face" instruction) are defined as courses in which zero percent of the content is delivered online. The remaining alternative, partially online (also called blended learning or hybrid learning) involves a course that is partially delivered online and partially delivered in the classroom (i.e., between 30 percent and 80 percent of the course content is delivered online).

A number of courses that incorporate Web-based supplements, such as podcasting, "wikis" and blogs, threaded discussions and Web-based assignments are frequently considered to be online courses. Courses that make use of these Web-based supplements are not considered online courses for this research but are, instead, regarded as traditional (hybrid/partially online) courses with online components or supplements.

\section{STUDIES RELATING TO THE ONLINE FORMAT}

Several studies indicate that performance is the same, regardless of whether a course is taken traditionally or online. Regarding student performance in online versus traditional classes, Daymont and Blau [3] found that undergraduate students perform equally well in both online and traditional sections. The study considered particular factors including class and major and found that the online students, while doing equally well, did not do better than their counterparts in traditional classrooms.

$\mathrm{Lu}, \mathrm{Yu}$ and Liu [10] found that none of the factors, except ethnic groups, showed any significant impact on students' learning performance in graduate Management Information Systems classes. Another study undertaken by Kleinman and Entin [9] contrasted online and traditional classroom teaching from both the instructor and student perspectives as related to two sections of an introductory Visual Basic programming course. While the online students were more positive about the value of the course, no difference in performance could be found between the online and the traditional methods of delivery. Another study of online instruction examined the traditional sections of Computer Literacy versus WebCT sections and found retention and grade distribution to be similar for both groups [14]. Conversely, research involving an 
analysis of student performance in online Computer Science courses concluded that Computer Science students enrolled in a traditional networking course outperformed the Computer Science students enrolled in the online section of the course [11].

Several studies indicated mixed results. Analysis of the data of a study in a Management Information Systems course indicated a significant difference between students grades in a traditional setting (85 percent) versus student grades in an online setting (81 percent) [17]. Similar results were found regarding an entry-level programming course: student grades in the online section averaged 78 percent while student grades in the traditional section averaged 84 percent. Another, more comprehensive study that involved seven courses in Computer Science and Information Systems showed mixed results: in some courses, online students have not performed as well as traditional students [16]. The authors found that in four upper-level courses (Programming Languages, Survey of Algorithms, Computer Organization II and Theory and Implementation of Programming Languages) taken by Computer Science majors, no significant differences in performance were found. However, three courses (Introduction to Programming Visual Basic, Management Information Systems and Database Systems) taken by students from many majors and minors showed significant differences in student performance. The authors concluded that some students taking an online course (who are academically equal to students taking a traditional course) are satisfied to trade a low grade for convenience. Additionally, students taking a course outside of their major do not want to spend much time on the course and will choose the online format because attendance is not required.

A study by Zhao, Lei, Yan and Tan [19] investigated factors that affect "effective” distance education. The empirical findings varied greatly and were not found to be significantly different from those of traditional instructional methods. However, the findings also offer evidence that not all content is appropriate for distance education and some students may not be able to benefit from the distance education delivery method.

Although students' perceptions of the advantages of online education may be positive, there are also disadvantages for students who have never taken an online course or who have little computer experience. A study by Wang, Newlin and Tucker [18] found that many students taking Web-based courses expressed feelings of intense anxiety about the technology. In addition, it was found that there are disadvantages in online courses for individuals who need a great deal of structure. Online courses are often self-paced and students who lack self-discipline may struggle.

A study by Dobbs, Waid and del Carmen [4] measured students' perceptions of online course experiences. The participants of the study were 100 students who were attending traditional, "face-to-face" (on-ground) courses and 180 students who were attending online classes. The authors found that more students perceived the traditional "face-to-face" courses to be easier than online classes. Student views about online education varied greatly between those who had never taken an online class and those who had actually taken such courses. Those students with no online class experience felt that the faculty would have low expectations but students who had taken at least one online course believed that high expectations were common with faculty. The study also found that the acceptance of online education increased as the number of online courses taken increased.

In another study Hannay and Newvine [8] found that students must possess greater discipline to succeed in an online course. Students who had never taken an online course were not confident that they could do as well in an online course as they would in an on-ground, "face-to-face", course. Additionally, students were skeptical about the opportunity of interaction with classmates in an online course and thought the online course would not cover the material in the same magnitude as the "face-to-face" course. 
In their study involving undergraduate management courses, Drennan, Kennedy and Pisarski [6] found that research subjects believed it was important to achieve a balance between the use of traditional, "face-toface”, lectures and emerging technologies. In another study involving undergraduate accounting students, researchers found that the hybrid or blended approach to online learning was superior to course content delivered entirely online. Specifically, the researchers determined that using technology as an exclusive course delivery method was considered insufficient [7].

A recent comprehensive 12-year experimental and quasi-experimental study utilizing meta-analysis conducted by the U. S. Department of Education found that a blend of online and "face-to-face" instruction has been more effective, which provides a rationale for the effort required to design and implement blended approaches [12]. This research also indicated that, despite what appears to be strong support for online learning applications, the studies in this meta-analysis do not demonstrate that online learning is superior as a medium. In many of the studies that involved a preference for online learning, the online and classroom conditions differed in terms of time spent, curriculum and pedagogy.

Finally, Downing and Chim [5], in a study involving online education and learning styles, found that preference for an active learning style has a positive effect on students' performance. Smith [15] identified two major factors for successful online learning: (a) self-management of learning and (b) comfort with elearning. Butler and Pinto-Zipp [2] further identified the three strongest preferences of the online learners: convenience, time management and interactivity.

\section{METHODS AND PROCEDURES}

The current research involved the administration of an online survey instrument that consisted of 34 closedended questions. This survey was administered during Academic Years 2010 to 2011 to students enrolled in CIS courses at two universities. One university is a public institution located in a rural setting with a total undergraduate enrollment of 7,419. The other university is a private institution located in a suburban setting with an undergraduate enrollment of 3,803. Both of the universities' CIS degree programs are accredited by ABET. The respondents of the private university consisted of undergraduate, graduate and post-graduate students; whereas, the respondents from the public university consisted only of undergraduate students. A total of 376 students responded to the initial survey and 245 students responded to the follow up survey. Responses from both surveys were used for this study.

The students completed the survey online while enrolled in either an on-ground, hybrid/partially online or online CIS course. The students submitted their anonymous results directly into an electronic database for analysis. The results of the survey were analyzed using SPSS statistical software. Statistical frequencies and statistical tests were used to answer the research questions posed in the introduction section.

\section{RESULTS}

In order to answer the first research question (Which delivery method (i.e., on-ground, online, hybrid/partially online) do students perceive as providing the best learning in regard to CIS subject areas?), the survey instrument asked the 245 respondents of the follow up survey to select the delivery method that they felt provided the best learning for each grouping of CIS-related topics. The available CIS groupings were: Software Development/ Programming, Network Administration/Security, Web Design/Web Graphics, Office Productivity Software, IT Project Management, Systems Analysis \& Design, Certification Courses (e.g., A+, N+), Operating Systems and Database and Business Intelligence (i.e., Data Warehousing, Data Mining). The results from these questions are summarized in Table 1.

Overall, research participants selected on-ground as the course delivery method that they perceived to provide the best learning (i.e., on-ground received the most votes for 10 out of 10 subject areas). 
Volume XII, No. 2, pp. 13-21, 2011

Hybrid/partially online was perceived to be the second highest delivery method for providing best learning. In fact, the online delivery method was the least selected method for 9 of the 10 subject areas, with the exception of the Office Productivity Software category. For this subject area, online was chosen over the hybrid/partially online format.

The second research question attempted to answer the following: "For each instructional method (i.e., online, hybrid/partially online, on-ground) should your school Offer More, Keep Offerings the Same or Offer Less courses that use a particular instructional method?" In order to answer the second research question, the survey instrument asked participants to select one of the three choices relating to each of the three delivery methods. The results are summarized in Table 2 .

As Table 2 illustrates, 41.22 percent of the respondents indicated that more on-ground or traditional "faceto-face" courses should be offered and only 5.31 percent felt that less on-ground courses should be offered. Although 39.59 percent were in favor of offering more online courses, 24.49 percent specified that less online courses should be offered. Finally, 50.61 percent, or just over half of the respondents, wanted more course offerings in the hybrid/partially online format; only 9.80 percent favored less courses being offered in this format.

In order to answer the third research question (i.e., Can a profile be developed for students who prefer the online delivery method based on the students' work habits (i.e., supervision, self-organization and interaction)?), the survey instrument asked participants to identify their work habits related to supervision, self-organization and interaction. The analysis of variance (ANOVA) test was used to determine any possible correlation between a student's work habits and his/her perceived effectiveness of online learning. The results from these survey questions are summarized in Tables 3a, 3b and 3c, respectively.

The first ANOVA test was used to detect any possible relationship between the amount of Supervision a student feels he/she needs and that student's perception of online learning effectiveness. Specifically, students were asked if they "work better without direct supervision" or if they "work better when someone is there to keep [them] focused." These responses were compared to the student's perceived effectiveness of online learning (i.e., "Very ineffective" through "Very effective"). As the results in Table 3a indicate, the F-Ratio shows a statistically significant relationship between Supervision Needed and Perceived Online Effectiveness, $F(1,188)=7.75, p=.006$. This result suggests that those students who "work better without direct supervision" tend to rate online learning as being more effective.

The second ANOVA test was used to detect any possible relationship between the Self-Organization of a student and that student's perception of online learning effectiveness. Specifically, students were asked if they perceived themselves as being "Well organized" or as "Having difficulty completing assignments and/or projects." Again, as in the first ANOVA test, these responses were compared to the student's perceived effectiveness of online learning. As the results in Table $3 \mathrm{~b}$ indicate, the F-Ratio shows a statistically significant relationship between Self-Organization and Perceived Online Effectiveness, $F$ $(1,188)=7.14, p=.008$. This result suggests that those students who describe themselves as being "Well organized" tend to rate online learning as being more effective.

Finally, the ANOVA test was used to detect any existing relationship between Classroom Interaction needed and the student's perceived online effectiveness. The students were asked to indicate if classroom interaction was "Not essential for learning and understanding," "Sometimes helpful for learning and understanding" or "Always helpful for learning and understanding." Again, the above responses were compared to the student's perceived effectiveness of online learning. As the results in Table 3c indicate, the F-Ratio shows a statistically significant relationship between Classroom Interaction and Perceived Online Effectiveness, $F(2,187)=18.53, p=.000$. This result suggests that those students who indicate 
Volume XII, No. 2, pp. 13-21, 2011

classroom interaction as being "Not essential to learning and understanding" tend to rate online learning as being more effective.

\section{CONCLUSIONS}

The present research surveyed undergraduate, graduate and post-graduate students to examine the questions: 1) Which delivery method (i.e., on-ground, online, hybrid/partially online) do students perceive as providing the best learning in regard to CIS subject areas? 2) For each instructional method (i.e., online, hybrid/partially online, on-ground) should your school Offer More, Keep Offerings the Same or Offer Less courses that use the instructional method? 3) Can a profile be developed for students who prefer the online delivery method based on the students' work habits (i.e., supervision, self-organization and interaction)?

In regard to the first research question, respondents perceived on-ground and then, hybrid/partially online, as formats which provide better learning than the online format, in relation to CIS areas of study. The only exception to the above findings involved the Office Productivity Software subject area. Regarding this subject area, the respondents felt that online provided better learning than hybrid/partially online.

As presented in the results section, for the second research question, respondents also indicated that more on-ground and hybrid/partially online courses should be offered, as opposed to online courses. One additional question on the survey asked the students, if given a choice to take the same course online or onground, would they select the online format. Of the 245 respondents, 151 (61.63 percent) indicated "No" and 94 respondents (38.37 percent) indicated "Yes." Another question on the survey asked the respondents if they would consider completing a CIS degree that is TOTALLY on-line. Of the 245 respondents, 185 (75.51 percent) indicated “No.”

Although the results cannot be generalized to all CIS/IS students in all CIS/IS programs, it may be inferred that the CIS/IS students in this study preferred on-ground delivery of course content for CIS-related topics. However, if online delivery is to be incorporated into a CIS curriculum, the current study suggests that universities that are adding more online courses in the CIS/IS area may want to pursue a hybrid approach (i.e., a combination of on-ground and online learning).

The hybrid approach was also supported in the Drennan, et al. [6] study involving undergraduate management students. In this 2005 study, the authors advocated the use of hybrid/blended learning as a way to maintain the more personal, "face-to-face" experience of on-ground learning, while still leveraging the convenience of online technologies.

Further, if a profile can be determined based on work habits, the student who would find the online delivery method to be most effective would have the following characteristics: 1) the ability to work independently (i.e., without direct supervision) 2) be well-organized 3) not require classroom interaction for learning and understanding of course material.

The above conclusions support the findings of past studies. For example, Wang, et al. [18] found that students who are not self-directed and not organized often struggle with online courses. In addition, Hannay and Newvine [8] also found that students must possess greater self-discipline in order to succeed in online courses. The Hannay and Newvine study also revealed that students tended to have negative perceptions of online courses because they feel online courses would not provide the same level of classroom interaction as traditional, on-ground instruction.

Finally, the inherent content of CIS courses must be considered in light of the current research findings. The current study surveyed students who were specifically enrolled in CIS courses. Since CIS courses and programs involve content that is "hands-on" and technically-oriented, some students may have difficulty 
Volume XII, No. 2, pp. 13-21, 2011

understanding such content in an environment that is not "face-to-face". The procedural nature of such course content may explain why CIS students, in the current study, did not prefer an online method of course delivery.

\section{REFERENCES}

1. Allen, I. E., \& Seaman, J. (2010), Learning On Demand: Online Education in the United States (2009). The Sloan Consortium. Retrieved from http://www.sloan-c.org

2. Butler, T. J., \& Pinto-Zipp, G. (2005-2006). Students' learning styles and their preferences for online instructional methods. Journal of Educational Technology Systems, 34(2), 199-221.

3. Daymont, T., \& Blau, G. (2008). Student Performance in Online and Traditional Sections of an Undergraduate Management Course. Journal of Behavioral and Applied Management, 9(3), 275-294.

4. Dobbs, R. R., Waid, C. A., \& del Carmen, A. (2009). Students' perceptions of online courses the effect of online course experience. The Quarterly Review of Distance Education, 10(1), 9-26.

5. Downing, K., \& Chim, T. M. (2004). Reflectors as online extraverts? Educational Studies, 30(3), 265-276.

6. Drennan, J., Kennedy, J., \& Pisarski, A. (2005). Factors affecting student attitudes toward flexible online learning in management education. Journal of Educational Research, 98(6), 331-339.

7. Flynn, A., Concannon, F., \& Bheachain, C. N. (2005). Undergraduate students' perceptions of technology-supported learning: The case of an accounting class. ELearning, 4(4), 427-444.

8. Hannay, M., \& Newvine, T. (2006), Perceptions of Distance-Learning: A Comparison of Online and Traditional Learning. MERLOT Journal of Online Learning and Teaching, 2(1) 1-11, Retrieved March 12, 2011 from http://jolt.merlot.org/documents/MS05011.pdf

9. Kleinman, J. and E. Entin. Comparison of In-Class and Distance-Learning Students' Performance and Attitudes in an Introductory Computer Science Course," Journal of Computing Sciences in Colleges, 17:6, 2002, pp. 206-219.

10. Lu, J., C. Yu and C. Liu. "Learning Style, Learning Patterns and Learning Performance in a WebCTBased Course," Information and Management, 40, 2003, pp. 497-507

11. McDonald, M., B. Dorn and G. McDonald. "A Statistical Analysis of Student Performance in Online Computer Science Courses," Proceedings of the 35th SIGCSE Technical Symposium on Computer Science Education, Norfolk, Virginia: 2004, pp. 71-74.

12. Means, B.; Toyama, Y.; Murphy, R.; Bakia, M.; Jones, K. (2009), Evaluation of Evidence-Based Practices in Online Learning: A Meta-Analysis and Review of Online Learning Studies October 11 2010

13. Patton, C. (2005) Faster, Cheaper, Better. District Administration, 41(5), 58-61. Retrieved From Education Research Complete database.

14. Reeves, T., P. Baxter and C. Jordan. "Teaching Computing Courses - Computer Literacy, Business Microcomputer Applications and Introduction to Programming Online Utilizing WebCT," Journal of Computing Sciences in Colleges, 18:1, 2002, pp. 290-300.

15. Smith, P. J. (2005). Learning Preferences and Readiness for Online Learning. Educational Psychology, 25(1), 3-12.

16. Ury, McDonald, McDonald and Dorn (2006). "Student Performance Online vs Onground: A Statistical Analysis of IS Courses,” Information Systems Education Journal, 4 (98).

17. Ury, G. (2005). "A Longitudinal Study Comparing Undergraduate Student Performance in Traditional Courses to the Performance in Online Course Delivery." The Information Systems Education Journal,3(20), retrieved February 18, 2011 from http://isedj.org/3/20/

18. Wang, A. Y., Newlin, M. H., \& Tucker, T. L. (2001). A discourse analysis of online classroom chats: Predictors of cyber-student performance. Teaching of Psychology, 28, 222-226.

19. Zhao, Y., Lei, J., Yan, B., \& Tan, S. (2005). What makes the difference? A practical analysis of research on the effectiveness of distance education. Teachers College Record, 107(8), 1836-1884. 
Volume XII, No. 2, pp. 13-21, 2011

Table 1: Best Learning by CIS Subject Area and Method of Delivery

Delivery Method Providing Best Learning

\begin{tabular}{lcccccc}
\hline \multirow{2}{*}{ Subject Area } & \multicolumn{2}{c}{ On-ground } & Online & \multicolumn{3}{c}{$\begin{array}{l}\text { Hybrid/Partially } \\
\text { Online }\end{array}$} \\
\cline { 2 - 7 } & Count & Percent & Count & Percent & Count & Percent \\
\hline System Analysis \& Design & 169 & $69.0 \%$ & 29 & $11.8 \%$ & 47 & $19.2 \%$ \\
\hline Project Management & 161 & $65.7 \%$ & 28 & $11.4 \%$ & 56 & $22.9 \%$ \\
\hline $\begin{array}{l}\text { Network Administration/ } \\
\text { Security }\end{array}$ & 169 & $69.0 \%$ & 29 & $11.8 \%$ & 47 & $19.2 \%$ \\
\hline $\begin{array}{l}\text { Software Development/ } \\
\text { Programming }\end{array}$ & 173 & $70.6 \%$ & 27 & $11.0 \%$ & 45 & $18.4 \%$ \\
\hline Web Design/ Graphics & 152 & $62.0 \%$ & 39 & $15.9 \%$ & 54 & $22.0 \%$ \\
\hline $\begin{array}{l}\text { Operating Systems } \\
\text { Watabase }\end{array}$ & 149 & $60.8 \%$ & 45 & $18.4 \%$ & 51 & $20.8 \%$ \\
\hline $\begin{array}{l}\text { Daffice/Productivity Software } \\
\text { Ondiness Intelligence (e.g. }\end{array}$ & 116 & $47.3 \%$ & 72 & $29.4 \%$ & 57 & $23.3 \%$ \\
\hline $\begin{array}{l}\text { Data Warehousing, } \\
\text { Data Mining) }\end{array}$ & 158 & $64.5 \%$ & 32 & $13.1 \%$ & 55 & $22.4 \%$ \\
\hline $\begin{array}{l}\text { Certification Courses } \\
\text { (e.g., A+, N+) }\end{array}$ & 158 & $64.5 \%$ & 42 & $17.1 \%$ & 45 & $18.4 \%$ \\
\hline
\end{tabular}

Table 2: Course Offerings and Method of Delivery

Delivery Method and Course Offerings

\begin{tabular}{lrrlrlll}
\hline \multirow{2}{*}{ Course Offerings } & \multicolumn{2}{l}{ On-ground } & Online & \multicolumn{3}{c}{$\begin{array}{l}\text { Hybrid/Partially } \\
\text { Online }\end{array}$} \\
\cline { 2 - 8 } & Count & Percent & Count & Percent & Count & Percent \\
\hline Keep the Same & 131 & $53.47 \%$ & 97 & $39.59 \%$ & 97 & $39.59 \%$ \\
\hline Offer Less Courses & 13 & $5.31 \%$ & 60 & $24.49 \%$ & 24 & $9.80 \%$ \\
\hline Offer More Courses & 101 & $41.22 \%$ & 88 & $35.92 \%$ & 124 & $50.61 \%$ \\
\hline
\end{tabular}


Volume XII, No. 2, pp. 13-21, 2011

Table 3a: ANOVA of Supervision and Online Effectiveness

Analysis of Variance (ANOVA) of Supervision Needed and Perception of Online Effectiveness

\begin{tabular}{lllllll}
\hline & & $\begin{array}{l}\text { Sum of } \\
\text { Squares }\end{array}$ & df & $\begin{array}{l}\text { Mean } \\
\text { Square }\end{array}$ & F & p \\
\hline $\begin{array}{l}\text { Overall Effectiveness }- \\
\begin{array}{l}\text { Completely Online } \\
\text { Supervision Needed }\end{array}\end{array}$ & Between Groups & 14.01 & 1 & 14.01 & $7.75^{* *}$ & .006 \\
\cline { 2 - 6 } & Within Groups & 339.89 & 188 & 1.81 & & \\
\hline & Total & 353.40 & 189 & & & \\
\hline
\end{tabular}

Note: $* *=p \leq .05$

Table 3b: ANOVA of Self-Organization and Online Effectiveness Analysis of Variance (ANOVA) of Self-Organization and Perception of Online Effectiveness

\begin{tabular}{lllllll}
\hline & & $\begin{array}{l}\text { Sum of } \\
\text { Squares }\end{array}$ & $\boldsymbol{d f}$ & $\begin{array}{l}\text { Mean } \\
\text { Square }\end{array}$ & $\boldsymbol{F}$ & $\boldsymbol{p}$ \\
\hline $\begin{array}{l}\text { Overall Effectiveness }- \\
\begin{array}{l}\text { Completely Online } \\
\text { Self Organization }\end{array}\end{array}$ & Between Groups & 12.94 & 1 & 12.94 & $7.14^{* *}$ & .008 \\
\cline { 2 - 7 } & Within Groups & 340.95 & 188 & 1.81 & & \\
\hline & Total & 353.90 & 189 & & & \\
& & & &
\end{tabular}

Note: $* *=p \leq .05$

Table 3c: ANOVA of Classroom Interaction and Online Effectiveness Analysis of Variance (ANOVA) of Classroom Interaction Needed and Perception of Online Effectiveness

\begin{tabular}{|c|c|c|c|c|c|c|}
\hline & & $\begin{array}{l}\text { Sum of } \\
\text { Squares }\end{array}$ & $d f$ & $\begin{array}{l}\text { Mean } \\
\text { Square }\end{array}$ & $F$ & $p$ \\
\hline \multirow{3}{*}{$\begin{array}{l}\text { Overall Effectiveness - } \\
\text { Completely Online * } \\
\text { Classroom Interaction } \\
\text { Needed }\end{array}$} & Between Groups & 58.54 & 2 & 29.27 & $18.53 * *$ & .000 \\
\hline & Within Groups & 295.35 & 187 & 1.58 & & \\
\hline & Total & 353.90 & 189 & & & \\
\hline
\end{tabular}

Note: $* *=p \leq .05$ 